\title{
Assessment in education-from early childhood to higher education
}

\author{
Stephan Gerhard Huber ${ }^{1} \cdot$ Guri Skedsmo $^{1,2}$
}

Published online: 31 August 2016

(C) Springer Science+Business Media New York 2016

Assessment is a daily business in education and exists in different forms, for different purposes and on different levels. Generally, assessment implies observing the outcomes of something and assigning a value to what is observed (Stake 1991). Consequently, assessments do not provide objective data, but through the course of assessment, aspects without value become systematically divided from the aspects considered to have great value (Scriven 1991). In this process, policy makers, educators and other important stakeholders are provided with opportunities to give 'interpretations in an operational way' (cf. Lundgren 1990, p. 35), which means the information can be used for specific purposes to guide and improve certain aspects of education. This can also lead to a situation where other aspects may be concealed, or at least receive less attention.

\section{Articles in this issue of EAEA 3/2016}

The four articles in this issue focus on aspects and topics related to assessment in education, ranging from early childhood to the role of assessment and learning outcomes in higher education.

From the perspective of recent developments in theorising learning, assessment and the mutual relationship between learning and assessment, which has emerged over the past 20-25 years, Havnes and Prøitz explore the role of learning outcomes in higher education. By bringing together theories of learning and well-known traits of learning

Guri Skedsmo

guri.skedsmo@ils.uio.no

Stephan Gerhard Huber

stephan.huber@phzg.ch

1 Institute for the Management and Economics of Education, University of Teacher Education Zug, Zug, Switzerland

2 Department of Teacher Education and School Research, University of Oslo, Oslo, Norway 
outcomes, they question whether the behaviourist approach has gained ground, leading to competence being conceptualised as 'to-do' achievements that can be specified and observed. Moreover, they point to several dilemmas and possible implications for the nature of learning processes in higher education if learning outcomes are used to foster compliance rather than critical, analytical thinking. They argue that using learning outcomes predominantly for policy, management and quality control purposes might actually weaken the learning outcomes' potential to inform teaching and learning. Although the analysis in this article relates to higher education, we would argue that these arguments are applicable to the whole education system.

Learning and assessment in higher education are also addressed by Roth, Ogrin and Schmitz. Due to the significance of self-regulated learning (SRL), and its underlying influence on both students' academic achievement and adult learning in general, they explore recent developments in the SRL field and the implications of these for measuring key characteristics of SRL. Their systematic review of studies applying various types of instruments developed and used during the past 25 years illustrates both gains and shortcomings. The authors conclude that there is great variety in the aspects measured, and in the definitions of SRL that form the basis for the instruments, and they argue that multi-approaches, such as verified survey instruments in combination with other approaches such as learning dialogues, should be tested further.

When learning outcomes become one of the main sources for improving teaching and learning, increased emphasis is placed on feedback and teachers' assessment literacy. In the third article, DeLuca, LaPointe-McEwan and Luhanga analyse assessment literacy standards in six regions (Australia, Canada, New Zealand, the UK, the USA and mainland Europe) to understand shifts in the assessment landscape over time and across regions, as well as assessment literacy measures developed post-1990 standards. Based on their analysis, the authors divide the past 25 years into three periods according to themes in the assessment standard documents, moving from an emphasis on summative and standardised use assessment towards an increased focus on Assessment for Learning, support for teachers and integrated approaches to assessment and learning after 2000. Interestingly, they find that the instruments used to measure assessment literacy have not followed recent developments in this field in terms of recognising the formative role of assessment, and the authors provide clear recommendations for the further development of literacy measures that more accurately align with teachers' current assessment demands.

Several studies have shown that differences in academic performance begin at an early stage and persist over time. Increasing attention has therefore been paid to measuring the quality of early childhood learning and development, from independent researchers to governments and international organisations. Although several new and innovative approaches to measuring and addressing quality in early childhood settings have been developed in recent years, they are not widely or consistently used. In the fourth article of this issue, Goldstein and Flake provide an argument-based framework for the validation of assessment systems in early childhood that allow for examining critical assumptions underlying the purposes of the assessments in use. They argue that if assessments are created to improve outcomes for young children, evidence is required to show how data are used to improve programmes. The validation of assessments therefore needs to start in the development process, where the assessment developers must consider not only the collection of items but the role the assessment plays in 
serving young children, which requires the joint agreement of stakeholders, resources, the support of educators and further coordinated system efforts.

\section{To promote learning or secure compliance}

A common theme across the articles is the argument that increased attention must be paid to aspects of assessment and their implications for learning and development. This starts with how learning outcomes are defined (see Havnes \& Prøitz), how assessments are designed, planned, implemented and (not least) validated (see Goldstein \& Flake), the use and assessment of learning strategies such as self-regulated learning (see Roth, Ogrin \& Schmitz) and the assessment and development of assessment literacy among teachers to promote learning (see DeLuca, LaPointe-McEwan \& Luhanga).

If the aim is to promote learning and development, and not to secure compliance with performance standards, the authors in this issue are concerned about stakeholders and those whose perspectives are taken into account in the formulation of learning outcomes, and how those outcomes are measured.

All the contributions urge us to think more comprehensively and differentially about assessment and learning, and the links between both. We need to realise that the effects produced by the tools and systems we put into play depend on the aims and purposes ascribed to them. They carry with them meanings and representations, and may produce not only the intended effects but also unintended ones.

More research is needed on the extent to which assessment systems are able to produce the feedback needed to initiate a change of practice to promote learning of students, teachers, leaders, policy makers, and support agents. Of course, the kind of information needed differs from actor to actor. Besides well-designed assessments, acceptance and knowledge of how to use the feedback, we argue that 'knowhow' strategies and 'feasibility' (e.g. resources or structures and processes) of using this information are required.

\section{References}

Lundgren, U. P. (1990). Educational policy-making, decentralisation and evaluation. In M. Granheim, M. Kogan, \& U. P. Lundgren (Eds.), Evaluation as policymaking. Introducing evaluation into a national decentralised educational system (pp. 23-41). London: Jessica Kingsley Publishers.

Scriven, M. (1991). Beyond formative and summative evaluation. In M. W. McLaughlin \& D. C. Phillips (Eds.), Evaluation and education: At quarter century (Ninetieth yearbook of the National Society for the Study of Education). Chicago: Chicago University Press.

Stake, R. (1991). Retrospective on "The countenance of educational evaluation". In M. W. McLaughlin \& D.

C. Phillips (Eds.), Evaluation and education: At quarter century (Ninetieth yearbook of the National Society for the Study of Education). Chicago: Chicago University Press. 